\title{
Hepatic and Renal Metabolism before and after Portasystemic Shunts in Patients with Cirrhosis
}

\author{
O. E. Owen, M. A. Mozzoli, F. A. Reichle, T. H. Kreulen, R. S. Owen, G. Boden, and M. Polansky \\ Departments of Medicine and Surgery, and the General Clinical Research Center, Temple University Health Sciences Center, \\ Philadelphia, Pennsylvania 19140
}

\begin{abstract}
Hepatic cirrhosis with portal hypertension and gastroesophageal hemorrhage is a disease complex that continues to be treated by surgical portasystemic shunts. Whether or not a reduction or diversion of portal blood flow to the liver adversely affects the ability of the liver to maintain fuel homeostasis via gluconeogenesis, glycogenolysis, and ketogenesis is unknown.

11 patients with biopsy-proven severe hepatic cirrhosis were studied before and after distal splenorenal or mesocaval shunts. Hepatic, portal, and renal blood flow rates and glucose, lactate, pyruvate, glycerol, amino acids, ketone bodies, free fatty acids, and triglyceride arteriovenous concentration differences were determined to calculate net precursor-product exchange rates across the liver, gut, and kidney. The study showed that hepatic contribution of glucose and ketone bodies and the caloric equivalents of these fuels delivered to the blood was not adversely affected by either a distal splenorenal or mesocaval shunt. In addition to these general observations, isolated findings emerged. Mesocaval shunts reversed portal venous blood and functionally converted this venous avenue into hepatic venous blood. The ability of the kidney to make a substantial net contribution of ketone bodies to the blood was also observed.
\end{abstract}

\section{Introduction}

Cirrhosis, especially alcoholic cirrhosis, with portal hypertension and massive gastroesophageal hemorrhage, is a disease complex of enormous cost (1). Various therapeutic approaches have been tried to control acute and recurrent bleeding. The use of propranolol is of questionable long-term benefit (2-5). Endoscopic sclerotherapy helps to control acute variceal hemorrhage $(4,6-$ 8 ), but does not prevent subsequent bleeding (9). Because of the limited success with these therapeutic approaches, hepatic cirrhosis with portal hypertension and gastroesophageal hemorrhage is a disease complex that is still treated by portasystemic shunts.

We previously showed (10) that the total number of caloric equivalents derived from ketone bodies, plus glucose added to the bloodstream by cirrhotic livers that could be terminally ox-

Dr. Reichle's present address is Department of Surgery, PresbyterianUniversity of Pennsylvania Medical Center, Philadelphia, PA 19104. Dr. Kreulen's present address is Department of Cardiology, Graduate Hospital, Philadelphia, PA 19146.

Address reprint requests to Dr. Owen, Temple University Hospital, 3401 North Broad St., Philadelphia, PA 19140.

Received for publication 20 August 1984 and in revised form 14 May 1985.

J. Clin. Invest.

(c) The American Society for Clinical Investigation, Inc.

0021-9738/85/09/1209/09 \$1.00

Volume 76, September 1985, 1209-1217 idized by peripheral tissues (brain), was less than the contributions made by normal livers, after both an overnight and a 3-d fast. Knowledge pertaining to the effects of surgical intervention on hepatic delivery of fuels to the blood is needed. Specifically, does reduction or diversion of portal blood flow to or away from the liver with an already reduced transhepatic portal blood flow adversely affect the limited ability of the liver to maintain fuel homeostasis via glycogenolysis, gluconeogenesis, and ketogenesis?

We have evaluated the outcome of elective surgical therapy on fuel homeostasis by assessing hemodynamic and metabolic measurements in unanesthetized patients with cirrhosis and portal hypertension before and after mesocaval or distal splenorenal (Warren) shunts. Some of the preshunt results contained in this study were previously published $(10,11)$.

\section{Methods}

Patients (Table I). 11 patients were studied with liver biopsy-proven cirrhosis. All patients were informed of the nature, purpose, and possible risks and benefits of the studies before giving their voluntary written consent. The study protocol was approved by the Institutional Research Review Board of Temple University Health Sciences Center. They entered the hospital with gastroeosphageal variceal hemorrhages secondary to hepatic cirrhosis and portal hypertension. After blood transfusion, hemostasis, and parenteral nutrition with vitamin supplements, they were transferred to the General Clinical Research Center at Temple University Hospital.

There were six male and five female patients. The mean \pm SEM age was $50 \pm 4$ yr. Body surface area was calculated from height and weight, irrespective of the presence or absence of edema or ascites. Although the heights and weights and thus the body surface areas were normal, most of the patients had clinical evidence of diminished muscle mass. Eight of eleven patients had ascites.

After stabilization, they were given diets designed to be anabolic, containing $>22 \mathrm{kcal} / \mathrm{kg}$ body wt with at least $1 \mathrm{~g}$ of protein $/ \mathrm{kg}$ body wt in addition to carbohydrates, fats, minerals, and vitamins. Those patients unable to consume this quantity of nourishment orally received supplementary parenteral glucose and amino acids (Amigen, Baxter Laboratories, Morton Grove, IL; or Freeamine, McGraw Laboratories, Irving, CA).

Laboratory data were obtained from analyzing peripheral venous serum or plasma after the patients received good nutrition for days to weeks in the hospital, and just before preoperative catheterization studies were performed. Total protein concentrations were normal or elevated in 10 of 11 patients, but albumin concentrations were decreased $(\leq 3.5$ $\mathrm{g} / \mathrm{dl})$ in 6 of 11 patients. Total bilirubin was increased $(\geq 1.2 \mathrm{mg} / \mathrm{dl})$ in 10 of 11 patients, and alkaline phosphatase activity was $>100 \mathrm{IU} /$ liter in five patients. No patient had evidence of renal disease.

Patient 8 had insulin-dependent diabetes mellitus. He received his 1 ist insulin injection $24 \mathrm{~h}$ before each catheterization study. Since his results were comparable with the other cirrhotic patients, they were included in the data.

Liver biopsies were performed and specimens were evaluated for the presence and type of cirrhosis. Patient 5 had primary biliary cirrhosis. 
All the other patients had severe micronodular, macronodular, or mixed nodular alcoholic cirrhosis. The degree of cirrhosis was quantitatively determined from photomicrographs of Masson's trichrome-stained specimens, using the cut-out and weigh method (10). The fibrotic tissue in each hepatic tissue biopsy varied from 19 to $75 \%$ (Table I). In addition, some of the specimens showed fatty changes and alcoholic hepatitis.

Part of the preshunt catheterization studies were for the purpose of measuring portal blood pressure and flow and for performing venous portal angiographic studies. Part of the postshunt studies were done to assess shunt patency and flow and to measure the metabolic consequences of shunt surgery. Eight patients were catheterized after an overnight fast $(8-10 \mathrm{~h})$. Four of these patients (No. 1 to 4 ) were selected for distal splenorenal shunts and the remaining four patients (No. 5 to 8) were selected for mesocaval shunts. Another three patients (No. 9 to 11) were catheterized after a 3-d fast and were selected for mesocaval shunts. All 11 patients underwent repeated catheterization studies ( 3 to $10 \mathrm{~d}$ postoperatively). The nutritional support and the duration of the fasts for each patient were similar before the pre- and postshunt catheterization studies. Therefore, combining the results from the overnight and 3-d fasts did not bias the data in regards to the ability of livers to release fuels as glucose and ketone bodies into the blood. On the other hand, during the preshunt catheterization study, access to the portal venous blood in all patients was gained through umbilicoportal cannulation. However, access to the portal venous blood during the postshunt studies was gained through the mesenteric venous catheters as well as the umbilicoportal cannulation.

Before the preoperative catheterization studies, patients were without evidence of acute medical illness. Before the postoperative catheterization studies, some patients had low grade temperature elevations accompanying recuperation from surgery. Anemia severe enough to cause hemodynamic alterations (12) was absent in all patients before both catheterization studies.

The techniques used for umbilicoportal cannulation and brachial artery and hepatic and renal vein catheterizations and the methods for determining cardiac output, hepatic, ${ }^{1}$ portal, and renal blood flow are published in detail (10). After the appropriate equilibration period (10), two sets of samples were collected simultaneously at 10-min intervals from the brachial artery and the portal, hepatic, and renal veins. Isovolumetric quantities of $5 \%$ human albumin in $0.9 \%$ saline and $0.9 \%$ saline were infused through the various catheters in each patient during each catheterization procedure to replace the blood withdrawn during each study. The locations of the catheters were checked immediately after each blood sampling period, and, later, the hepatic and renal venous catheter positions were chemically confirmed by arteriovenous concentration differences for indocyanine green dye and sodium para-aminohippurate.

After blood sampling was completed, hepatopedal or hepatofugal blood flow was determined by the Lipiodol (E. Fougera and Co., Inc., Hicksville, NY) droplet method (10).

Chemical measurement. Analytical methods and precision for determining blood glucose, lactate, pyruvate, glycerol, alanine, glutamine, glutamate, $\beta$-hydroxybutyrate $(\beta \mathrm{OHB}){ }^{2}$ acetoacetate (AcAc), doubleextracted plasma free fatty acids (FFA), and triglycerides are published (14-16). Arterial and venous substrate concentrations were determined simultaneously in duplicate or triplicate.

Regional exchange rates. The quantities of substrates removed or released from or into the blood were calculated from the regional arte-

1. To avoid overloading the cirrhotic liver, we used a priming dose of only $2.5 \mathrm{mg}$ and a continuous dose of only $0.35 \mathrm{mg} / \mathrm{min}$ of indocyanine green dye mixed with $5 \%$ human albumin. The time period for the continuous infusion of dye was 15-30 min before the first arteriovenous blood samples were drawn. Thus, we used a low dose of dye and a short infusion period. The validity of using this dye technique to calculate hepatic metabolism has been confirmed by indirect calorimetry and ${ }^{14} \mathrm{C}$ tracer techniques (13). riovenous concentration differences multiplied by the regional blood or plasma flow rate and corrected to $1.73-\mathrm{m}^{2}$ body surface area.

The caloric equivalents of the fuels added to the blood by the liver were calculated from measuring the glucose released corrected for recycled lactate and pyruvate plus the ketone bodies released (10). Carbon atom balance across the kidneys was calculated from the total number of carbon atoms entering in arterial blood and exiting in renal venous blood contained in glucose, lactate, pyruvate, glycerol, alanine, glutamine, glutamate, FFA, triglycerides, AcAc, and $\beta-O H B$.

Statistical analyses. Multivariate analysis of variance (MANOVA; Hotelling $\mathrm{T}^{2}$ tests) for repeated-measurements (17) were used to determine (a) whether there were differences in arterial concentrations before and after surgery, $(b)$ whether arteriovènous concentration differences were significantly different from zero, and $(c)$ whether pre- and postshunt arteriovenous concentration differences and regional exchange rates were significantly different. MANOVA were done separately for arterial concentrations, arteriovenous concentration differences, and hepatic, and renal exchange rates, and separately for glucose and its precursors and FFA and its derivatives. When a Hotelling $\mathrm{T}^{2}$ test indicated that there was at least one statistically significant change among the variables examined, paired Student's $t$ test(s) was used to identify which variable(s) was altered. ${ }^{3}$ In addition, the paired Student' $t$ test was used to compare pre- and postshunt blood flow rates, and arteriorenal venous carbon atom differences. Most values are expressed as the mean + SEM, but some values are given as ranges. The ranges are used to depict the heterogeneity of the patients' results. Individual patient data are presented to illustrate specific changes.

\section{Results}

Preamble. The results given primarily address metabolic changes across the liver and kidney before and after portasystemic shunts. Previous publications contrasted normal humans with cirrhotic patients (10) and hemodynamic changes induced by portasystemic shunts (11).

During these catheterization studies steady-state conditions existed.

As we noted before, large negative (release) or positive (uptake) arteriovenous concentration differences cannot be explained by technical errors inherent in measuring blood or plasma substrate concentrations (10).

The individual hemodynamic results for the overnight and 3-d-fast patients before and after distal splenorenal or mesocaval shunts are given separately so that hemodynamic differences between the shunts can be displayed. The metabolic measurements across the liver for patients with distal splenorenal and mesocaval shunts were combined. Since overnight fasted cirrhotic patients exhibit a metabolic profile that is similar to a more advanced state of starvation (10), the duration of the fast was largely disregarded. However, the unexpected findings relating to substrate concentrations in the portal and renal veins

\footnotetext{
2. Abbreviations used in this paper: AcAc, acetoacetate; A-HV, arteriohepatic venous; A-PV, arterioportal venous; A-RV, arteriorenal venous; $\beta$-OHB, $\beta$-hydroxybutyrate; FFA, free fatty acids; MANOVA, multivariate analysis of variance.

3. Hotelling $\mathrm{T}^{2}$ test determines whether at least one of the variables differ, but does not identify the specific variable(s). Hotelling $\mathrm{T}^{2}$ tests ensure that Type I error rates do not exceed 0.05 when large numbers of $t$ tests are done in the same study. However, Hotelling $\mathrm{T}^{2}$ tests are less powerful tests than the paired Student's $t$ tests when the sample sizes are small as were ours, and hence, tend to miss significant differences and cause a high Type II error rate. Therefore, our probability estimates are extremely conservative.
} 


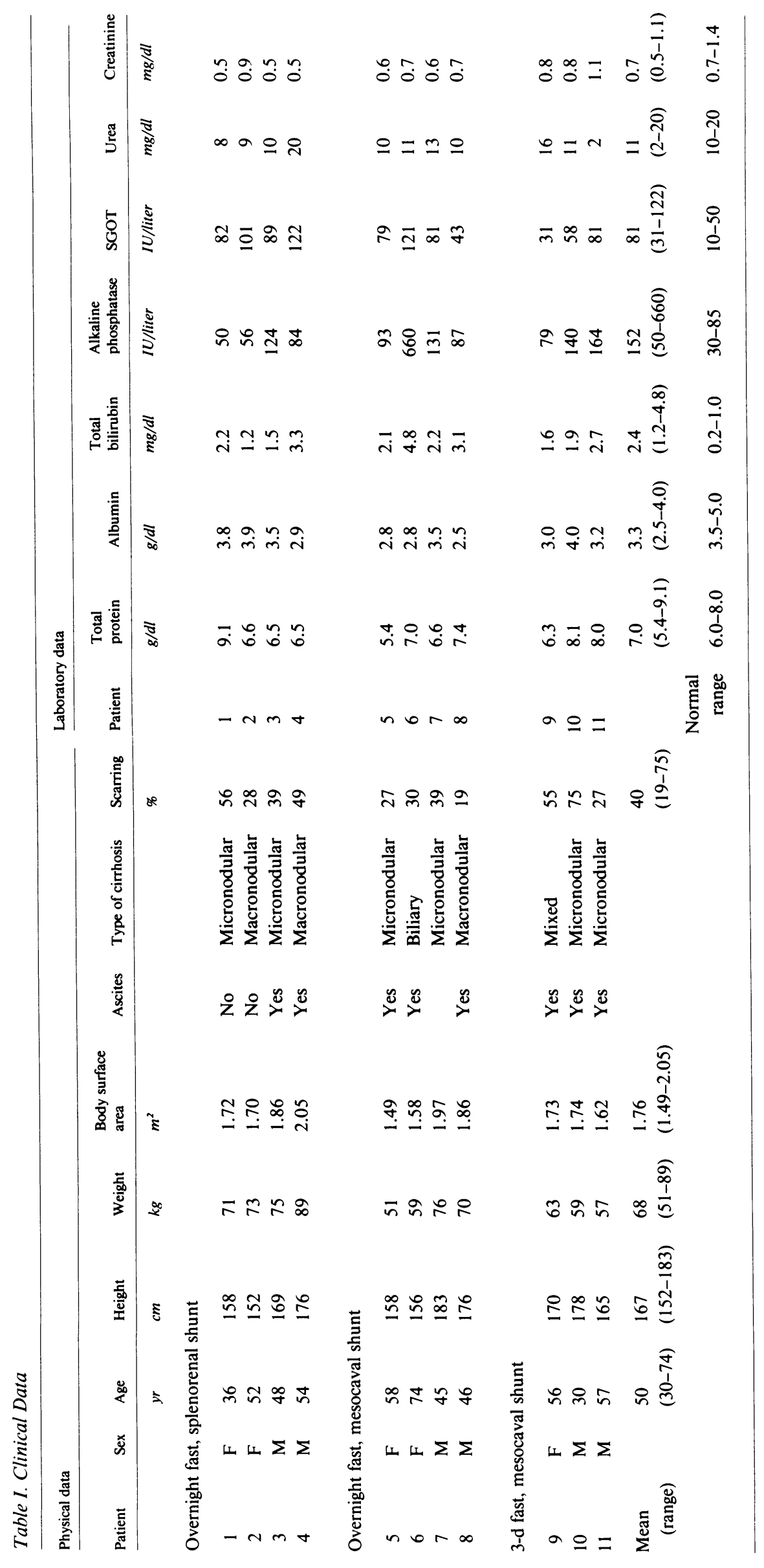


after portasystemic shunts required individualization of some of the data.

Blood flow rates (Table II). Cardiac output before shunting was $5.80 \pm 0.66 \mathrm{liter} / \mathrm{min}$ and rose postoperatively to $7.39 \pm 0.47$ liter/min $(P<0.05)$. Total hepatic blood flow was not significantly affected by the shunts being $1,752 \pm 286 \mathrm{ml} / \mathrm{min}$ and $1,772 \pm 415 \mathrm{ml} / \mathrm{min}$ before and after shunting, respectively. Portal blood flow was prograde (hepatopedal) in all patients before surgery. In those patients from which measurements were available, a reversal of hepatopedal blood flow to retrograde (hepatofugal) flow occurred in four of six patients after mesocaval shunts. In patient 10 , technical problems prevented portal blood flow measurements. In patient 11 , the Lipiodol droplets in the portal blood oscillated at the time of measurement. Therefore, portal blood flow was recorded as 0 . There was no significant hemodynamic effect of portasystemic shunt on renal blood flow. Before surgery it was $1,188 \pm 110 \mathrm{ml} / \mathrm{min}$ and after surgery it was $1,151 \pm 135 \mathrm{ml} / \mathrm{min}$.

Arterial concentrations and arteriovenous concentration differences (Tables III and IV). The arterial whole blood or plasma substrate concentrations of glucose, alanine, glutamine, glutamate, FFA, and triglyceride pre- and postshunt values were indistinguishable (MANOVA). Hyperketonemia existed during the preshunt catheterization studies, and the mean AcAc and $\beta$ OHB concentrations rose two- to threefold postshunt, but these changes were not statistically significant.

Pre- and postshunt arteriohepatic venous (A-HV) concentration differences were comparable and show splanchnic uptake of the gluconeogenic precursors (lactate, pyruvate, glycerol, al- anine, and glutamine) and release of glucose and glutamate in all patients. There was also pre- and postshunt a comparable positive (uptake) A-HV difference for plasma FFA and a comparable negative (release) difference for blood AcAc and $\beta-O H B$ and for plasma triglycerides.

Preshunt there were no significant arterioportal venous (APV) concentration differences for glucose, lactate, pyruvate, glycerol, glutamate, or FFA. The extrahepatic splanchnic tissues extracted AcAc and $\beta-\mathrm{OHB}$ and glutamine and released alanine. Postshunt there were large variations among A-PV concentration differences due to the change in hepatopedal to hepatofugal portal blood flow in patients with mesocaval shunts and changes in the sites from which portal venous blood samples were obtained before and after the shunts. Postshunt, only glycerol and glutamine were extracted, and no substrate was released by extrahepatic splanchnic tissues. Nonetheless, there were physiological differences. This was exemplified by patient 9 , who had an umbilicoportal venous cannula inserted for the preshunt study and an umbilicoportal venous cannula inserted during the mesocaval shunt operation for the postshunt study. Portal venous blood flow was reversed by the mesocaval shunt, as were the pre- and postshunt A-PV concentration differences for glucose (78 to $-279 \mu \mathrm{mol} / \mathrm{liter})$, AcAc ( -12 to $-604 \mu \mathrm{mol} / \mathrm{liter})$, and $\beta-\mathrm{OHB}$ (12 to $-314 \mu \mathrm{mol} / \mathrm{liter}$ ). By contrast, patient 7 had an umbilicoportal venous cannula inserted for the preshunt study and an inferior mesenteric venous cannula inserted during the mesocaval shunt operation. Postshunt portal blood flow was hepatofugal, but this did not reverse inferior mesenteric venous blood flow or have a significant effect on arterial-inferior mesenteric

Table II. Hemodynamic Measurements in Cirrhotic Patients

\begin{tabular}{|c|c|c|c|c|c|c|c|c|}
\hline \multirow[b]{2}{*}{ Patient } & \multicolumn{2}{|c|}{ Cardiac output } & \multicolumn{2}{|c|}{ Hepatic blood flow } & \multicolumn{2}{|c|}{ Portal blood flow } & \multicolumn{2}{|c|}{ Renal blood flow } \\
\hline & Preshunt & Postshunt & Preshunt & Postshunt & Preshunt & Postshunt & Preshunt & Postshunt \\
\hline & $\min$ & $\min$ & $\mathrm{ml} / \mathrm{min}$ & $\mathrm{ml} / \mathrm{min}$ & & & $\mathrm{ml} / \mathrm{min}$ & $\mathrm{ml} / \mathrm{min}$ \\
\hline \multicolumn{9}{|c|}{ Overnight fast, splenorenal shunt } \\
\hline 1 & 5.31 & 7.30 & 1,442 & 5,601 & Pedal & Pedal & 1,340 & 944 \\
\hline 2 & 5.44 & 4.57 & 796 & 430 & Pedal & Pedal & 610 & 524 \\
\hline 3 & 6.72 & 7.08 & 1,699 & 1,398 & Pedal & Pedal & 1,487 & 1,206 \\
\hline 4 & 9.53 & 7.84 & 1,264 & 1,524 & Pedal & Pedal & 1,433 & 1,146 \\
\hline
\end{tabular}

Overnight fast, mesocaval shunt

\begin{tabular}{|c|c|c|c|c|c|c|c|c|}
\hline 5 & 5.30 & 10.07 & 1,093 & 880 & Pedal & Fugal & 788 & 754 \\
\hline 6 & 7.48 & 7.53 & 1,370 & 1,244 & Pedal & Fugal & 1,005 & 747 \\
\hline 7 & 5.66 & 9.45 & 2,043 & 2,416 & Pedal & Fugal & 1,239 & 1,510 \\
\hline 8 & 8.66 & 8.45 & 3,941 & 1,996 & & & 1,397 & 1,457 \\
\hline \multicolumn{9}{|c|}{ 3-d fast, mesocaval shunt } \\
\hline 9 & 3.69 & 5.92 & 1,264 & 1,248 & Pedal & Fugal & 890 & 951 \\
\hline 10 & 2.40 & 6.46 & 1,263 & 1,661 & Pedal & - & 1,006 & 2,136 \\
\hline 11 & 3.58 & 6.66 & 3,098 & 1,100 & Pedal & 0 & 1,875 & 1,288 \\
\hline \multirow[t]{2}{*}{ Mean \pm SEM } & 5.80 & 7.39 & 1,752 & 1,772 & & & 1,188 & 1,151 \\
\hline & 0.66 & 0.47 & 286 & 415 & & & 110 & 135 \\
\hline$P$ & \multicolumn{2}{|c|}{$<0.05$} & \multicolumn{2}{|c|}{ NS } & & & \multicolumn{2}{|c|}{ NS } \\
\hline
\end{tabular}

Pedal, hepatopedal; fugal, hepatofugal. 
Table III. Arterial Concentrations and Arteriovenous Concentration Differences

\begin{tabular}{|c|c|c|c|c|c|c|c|c|}
\hline & \multicolumn{2}{|l|}{ Artery $(n=11)$} & \multicolumn{2}{|l|}{ A-HV $(n=11)$} & \multicolumn{2}{|c|}{ A-PV $(n=10)$} & \multicolumn{2}{|c|}{$\mathrm{A}-\mathrm{RV}(n=11)$} \\
\hline & Preshunt & Postshunt & Preshunt & Postshunt & Preshunt & Postshunt & Preshunt & Postshunt \\
\hline Glucose & $5,793 \pm 583$ & $5,576 \pm 816$ & $-365 \pm 42^{*}$ & $-473 \pm 56^{*}$ & $+49 \pm 30$ & $-2 \pm 44$ & $-1 \pm 20$ & $-70 \pm 33$ \\
\hline Lactate & $678 \pm 38$ & $867 \pm 98$ & $+263 \pm 19^{*}$ & $+357 \pm 33^{*}$ & $-28 \pm 22$ & $+52 \pm 32$ & $+23 \pm 19$ & $+69 \pm 31$ \\
\hline Pyruvate & $82 \pm 5$ & $102 \pm 10$ & $+24 \pm 4^{*}$ & $+31 \pm 4^{*}$ & $-6 \pm 6$ & $+7 \pm 6$ & $+5 \pm 3$ & $+8 \pm 2 *$ \\
\hline Glycerol & $89 \pm 7$ & $111 \pm 7$ & $+54 \pm 6^{*}$ & $+67 \pm 9 *$ & $+6 \pm 8$ & $+30 \pm 12^{*}$ & $+38 \pm 6^{*}$ & $+56 \pm 7^{*}$ \\
\hline Alanine & $204 \pm 15$ & $244 \pm 21$ & $+68 \pm 9 *$ & $+104 \pm 13^{*}$ & $-38 \pm 6^{*}$ & $-10 \pm 16$ & $-17 \pm 5^{*}$ & $-22 \pm 7^{*}$ \\
\hline Glutamine & $367 \pm 37$ & $363 \pm 37$ & $+59 \pm 10^{*}$ & $+94 \pm 14^{*}$ & $+58 \pm 16^{*}$ & $+73 \pm 26^{*}$ & $+72 \pm 9^{*}$ & $+62 \pm 10^{*}$ \\
\hline Glutamate & $139 \pm 9$ & $135 \pm 18$ & $-25 \pm 4^{*}$ & $-24 \pm 4^{*}$ & $+3 \pm 4$ & $-1 \pm 3$ & $-1 \pm 5$ & $-9 \pm 3^{*}$ \\
\hline Plasma FFA & $918 \pm 63$ & $991 \pm 95$ & $+198 \pm 30^{*}$ & $+264 \pm 47^{*}$ & $-9 \pm 38$ & $+29 \pm 64$ & $+31 \pm 27$ & $+26 \pm 24$ \\
\hline Plasma triglycerides & $597 \pm 103$ & $651 \pm 110$ & $-34 \pm 10^{*}$ & $-22 \pm 17$ & $-14 \pm 8$ & $+27 \pm 22$ & $+1 \pm 12$ & $+13 \pm 15$ \\
\hline AcAc & $216 \pm 69$ & $468 \pm 185$ & $-125 \pm 25^{*}$ & $-230 \pm 72^{*}$ & $+6 \pm 3^{*}$ & $-78 \pm 60$ & $+2 \pm 4$ & $-5 \pm 8$ \\
\hline$\beta$-ОНB & $380 \pm 104$ & $1,077 \pm 446$ & $-115 \pm 24^{*}$ & $-156 \pm 68^{*}$ & $+31 \pm 6^{*}$ & $-14 \pm 38$ & $+22 \pm 6 \ddagger$ & $+2 \pm 22$ \\
\hline Total ketone bodies & $595 \pm 170$ & $1,545 \pm 630$ & $-241 \pm 46^{*}$ & $-385 \pm 121^{*}$ & $+38 \pm 8^{*}$ & $-91 \pm 94$ & $+24 \pm 7 \ddagger$ & $-4 \pm 28$ \\
\hline
\end{tabular}

Values are expressed as micromoles/liter. Negative $(-)$ values denote release while positive $(+)$ values denote uptake. * Concentration differences statistically different from zero $(P<0.05)$. $¥$ Although renal uptake of $\beta$-OHB and total ketone bodies are insignificant according to MANOVA test, both are extracted according to the paired Student's $t$ test.

venous blood glucose, AcAc, or $\beta$-OHB concentration differences.

Pre- and postshunt, the arteriorenal venous (A-RV) concentration differences were indistinguishable and positive for glycerol and glutamine and negative for alanine (MANOVA). Of special interest were the findings pertinent to glucose and $\beta$-OHB. Preshunt A-RV concentration differences for glucose were small and insignificant, but 10 of 11 patients showed renal extraction of $\beta$-OHB. Postshunt the A-RV concentration differences varied widely for glucose and ketone bodies. Alanine A-RV concentration difference remained negative and unchanged from the preshunt value. Mean pre- and postshunt values for A-RV triglyceride concentration differences were also unimpressive; individual differences were remarkable in half the patients. As a group there was no significant mean release or uptake of glucose, $\beta$-OHB, or AcAc postoperatively.

Special comments are needed to evaluate the glucose and ketone-body A-RV concentration differences before and after surgery because the findings were striking. Large A-RV concentration differences cannot be explained by technical limitations for measuring substrates or by minute differences in water content of plasma across the renal vascular bed. Postshunt 5 of eight patients fasted overnight, and all 3-d-fast patients, released glucose from their kidneys (Table IV). Patient 8 was the extreme example of renal glucose release. His A-RV glucose concentration difference was $-315 \mu \mathrm{mol} / \mathrm{liter}(5.7 \mathrm{mg} / \mathrm{dl})$. Postshunt 7 of 11 patients had renal release of AcAc and/or $\beta-O H B$. Patient 9 was the extreme example of renal ketone-body release. Her A-RV concentration difference for AcAc was $-80 \mu \mathrm{mol} / \mathrm{liter}$ and for $\beta$-OHB was $-188 \mu \mathrm{mol} / \mathrm{liter}$.

Since the kidney does not store fuels in depots, the carbon atoms in substrates removed from the arterial blood must be released into the renal venous blood or excreted in the urine. The quantity of $\mathrm{CO}_{2}$ release is very small (18) and the amounts of glucose and ketone bodies lost in the urine are trivial at the concentrations present in this study (Table III) $(19,20)$.

When the sum (number) of the renal venous carbon atoms in glucose, lactate, pyruvate, glycerol, alanine, glutamine, glu- tamate, FFA, triglycerides, AcAc, and $\beta-\mathrm{OHB}$ were subtracted from the sum (number) of the arterial carbon atoms, the preshunt difference was $1.0 \pm 0.9$ carbon/liter and postshunt difference was $1.7 \pm 1.0$ carbon/liter (Table IV). These insignificant differences show that there was a close balance of total substrate carbons across the kidney, and that the loss of carbon atoms from these substrates for oxidative metabolism $\left(\mathrm{CO}_{2}\right)$ or into the urine was too small to be detected by this calculation method.

Net regional exchange rates (Table $V$ ). Regional uptake or release rates were calculated by multiplying the arteriovenous concentration (Tables III and IV) differences across the liver and kidney (Tables III and IV) by hepatic and renal blood or plasma flow rates (Table II). Hepatic blood supply is derived from the hepatic artery and portal vein. However, the A-PV concentration differences of substrate were either small or nonexistent before surgery. Therefore, disregarding extrahepatic splanchnic tissue, substrate flux rates before portasystemic shunts introduced minor or no errors in assuming that net splanchnic exchange rates closely reflect net hepatic exchange rates. Postshunt, the A-PV concentration differences varied widely due to directional changes in portal flow in patients with mesocaval shunts. This complex situation prevented assessment of postshunt extrahepatic splanchnic tissue metabolic exchange rates.

Preshunt net splanchnic (hepatic) glucose release was $577 \pm 96$ $\mu \mathrm{mol} / \mathrm{min}$ per $1.73 \mathrm{~m}^{2}$. Cirrhotic patients characteristically have hyperglucagonemia (21-23), and if the sum of gluconeogenic precursors (lactate + pyruvate + glycerol + amino acid equivalents ${ }^{4}$ ) were quantitatively converted into and released as glucose (24-26), then $\sim 352 \pm 50 \mu \mathrm{mol} / \mathrm{min}$ per $1.73 \mathrm{~m}^{2}$, or $61 \%$ of net hepatic glucose production, can be accounted for by gluconeogenesis. Postshunt net hepatic glucose release was $695 \pm 116$ $\mu \mathrm{mol} / \mathrm{min}$ per $1.73 \mathrm{~m}^{2}$; gluconeogenic precursors accounted for $433 \pm 60 \mu \mathrm{mol} / \mathrm{min}$ per $1.73 \mathrm{~m}^{2}$, or $62 \%$ of the released glucose. The increased postshunt value for net glucose release was not significant.

4. Amino acid equivalents were calculated by assuming that alanine uptake is $\sim 45 \%$ of the total splanchnic gluconeogenic amino acid uptake. 
Table IV. Arteriorenal Substrate Concentration* and Total Carbon Atom Differences

\begin{tabular}{|c|c|c|c|c|c|c|c|c|c|}
\hline \multirow[b]{2}{*}{ Patient } & \multicolumn{2}{|l|}{ Glucose } & \multicolumn{2}{|l|}{ Lactate } & \multicolumn{2}{|c|}{ Pyruvate } & \multicolumn{2}{|c|}{ Glycerol } & Alanine \\
\hline & Pre- & Post- & Pre- & Post- & Pre- & Post- & Pre- & Post- & Pre- \\
\hline \multicolumn{10}{|c|}{ Overnight fast, splenorenal shunt } \\
\hline 1 & -75 & -24 & +83 & +48 & +7 & 0 & +42 & +48 & -9 \\
\hline 2 & +37 & -78 & +43 & +120 & +6 & 0 & +67 & +108 & -24 \\
\hline 3 & -78 & -142 & -53 & -30 & -17 & +12 & +17 & +64 & -34 \\
\hline 4 & -36 & -98 & +4 & +342 & +5 & +20 & +46 & +82 & -19 \\
\hline
\end{tabular}

Overnight fast, mesocaval shunt

\begin{tabular}{|c|c|c|c|c|c|c|c|c|c|c|}
\hline 5 & -91 & +87 & -94 & +50 & 0 & +10 & +53 & +60 & -44 & -20 \\
\hline 6 & +112 & +34 & -25 & -56 & +4 & +10 & +31 & +75 & -26 & -15 \\
\hline 7 & +28 & +22 & +100 & +35 & +6 & +4 & +29 & +30 & +12 & -67 \\
\hline 8 & +82 & -315 & +20 & +28 & +4 & -1 & +40 & +28 & -13 & -43 \\
\hline
\end{tabular}

3-d fast, mesocaval shunt

$\begin{array}{lrrrrrrrrrr}9 & -39 & -54 & +118 & +86 & +10 & +24 & +59 & +54 & -13 & -35 \\ 10 & +40 & -141 & +36 & +52 & +8 & +10 & +28 & +34 & -18 & -4 \\ 11 & +12 & -62 & +17 & +83 & +20 & +4 & +3 & +38 & -2 & -11 \\ \text { Mean }+ \text { SEM } & -1 & -70 & +23 & +69 & +5 & +8 & +38 & +56 & -17 & -22 \\ & 20 & 33 & 19 & 31 & 3 & 2 & 6 & 7 & 5\end{array}$

$P$

NS, not significant; Post, postshunt; Pre, preshunt; TG, triglycerides. * Values are expressed as micromoles per liter. Negative ( - ) values denote release, while positive $(+)$ values denote uptake.

Preshunt net splanchnic (hepatic) AcAc, $\beta$-OHB, and total ketone body production rates were $204 \pm 48,181 \pm 36$, and $386 \pm 77 \mu \mathrm{mol} / \mathrm{min}$ per $1.73 \mathrm{~m}^{2}$, respectively. Postshunt hepatic AcAc, $\beta-\mathrm{OHB}$, and total ketone body production rates were $365 \pm 115,214 \pm 91$, and $579 \pm 173 \mu \mathrm{mol} / \mathrm{min}$ per $1.73 \mathrm{~m}^{2}$, respectively. None of these increases were significant.

Preshunt, the liver extracted $22 \pm 2 \%$ of the incoming plasma FFA, or $218 \pm 47 \mu \mathrm{mol} / \mathrm{min}$ per $1.73 \mathrm{~m}^{2}$. An estimated $47 \pm 7 \%$ of the FFA were converted into ketone bodies (14). Postshunt, $26 \pm 3 \%$ or $261 \pm 43 \mu \mathrm{mol} / \mathrm{min}$ per $1.73 \mathrm{~m}^{2}$ of FFA were extracted, and $\sim 48 \pm 11 \%$ were converted into ketone bodies. All these pre- and postshunt values were statistically indistinguishable.

When the production rates of glucose and ketone bodies were converted to caloric equivalents and summed, no significant differences emerge between the pre- and postshunt values (Fig. 1). Before and after surgery the liver delivers $498 \pm 82 \mathrm{cal} / \mathrm{min}$ per $1.73 \mathrm{~m}^{2}$ and $649 \pm 116 \mathrm{cal} / \mathrm{min}$ per $1.73 \mathrm{~m}^{2}$, respectively.

All cirrhotic livers before and after shunts contributed glucose and ketone bodies to the blood. The kidneys in these patients, however, behaved in a mixed and unexpected manner. Only the renal net exchange rates for the two most unusual patients are given. The kidneys of patient 8 released $400 \mu \mathrm{mol} / \mathrm{min}$ per $1.73 \mathrm{~m}^{2}\left(72 \mathrm{mg} / \mathrm{min}\right.$ per $\left.1.73 \mathrm{~m}^{2}\right)$ of glucose into the blood. Patient 9 released $186 \mu \mathrm{mol} / \mathrm{min}$ per $1.73 \mathrm{~m}^{2}(19.3 \mathrm{mg} / \mathrm{min}$ per $\left.1.73 \mathrm{~m}^{2}\right)$ of $\beta-\mathrm{OHB}$ and $80 \mu \mathrm{mol} / \mathrm{min}$ per $1.73 \mathrm{~m}^{2}(8.2 \mathrm{mg} / \mathrm{min}$ per $1.73 \mathrm{~m}^{2}$ ) of AcAc, for a total quantity of $266 \mu \mathrm{mol} / \mathrm{min}$ per $1.73 \mathrm{~m}^{2}$ of ketone bodies released into the blood. Again, it should be noted that these two patients were the extremes of the 11 patients studied. As a group there was no significant mean release or uptake of glucose, $\beta$-OHB or AcAc postoperatively.

\section{Discussion}

This study was designed to determine whether or not surgical portasystemic shunts in patients with severe alcoholic cirrhosis adversely affected the ability of liver to maintain fuel homeostasis. The patients served as their own controls. They were arbitrarily selected for a distal splenorenal or mesocaval shunt after they were well-nourished in our General Clinical Research Center. Our specific goal was to measure the hepatic contributions of glucose and ketone bodies to the blood before and after a portasystemic shunt. We studied a limited number of patients, and our findings may not be applicable to all patients with severe hepatic cirrhosis, and especially to those who undergo emergency surgical procedures. Nonetheless, this study clearly showed that the ability of the liver to continue its important role in maintaining fuel homeostasis by adding glucose and ketone bodies to the blood was not adversely affected by either a distal splenorenal or mesocaval shunt (Fig. 1). Preshunt, the quantities of glucose and AcAc plus $\beta$-OHB contributed to the blood were $577 \pm 96$ and $386 \pm 77 \mu \mathrm{mol} / \mathrm{min}$ per $1.73 \mathrm{~m}^{2}$, respectively. Postshunt, the quantities of glucose and ketone bodies were $695 \pm 116$ and $579 \pm 173 \mu \mathrm{mol} / \mathrm{min}$ per $1.73 \mathrm{~m}^{2}$, respectively. The postoperative glucose and ketone body production rates were not statistically different. Furthermore, the caloric equivalents of these fuels delivered to the blood before $(498 \pm 82 \mathrm{cal} / \mathrm{min}$ per $\left.1.73 \mathrm{~m}^{2}\right)$ and after $\left(649 \pm 16 \mathrm{cal} / \mathrm{min}\right.$ per $\left.1.73 \mathrm{~m}^{2}\right)$ surgery were comparable.

Net splanchnic (liver) production rates of glucose and ketone bodies were calculated by multiplying arteriohepatic venous concentration differences by hepatic blood flow rates. Patient 1 


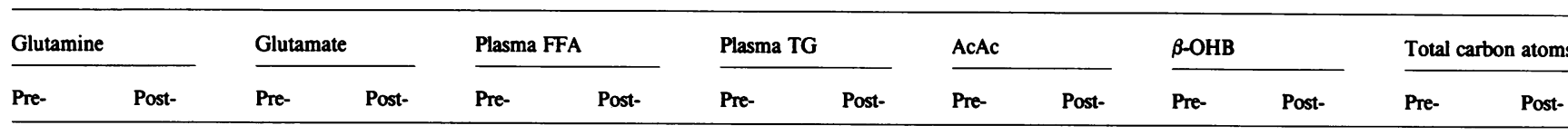

$\begin{array}{rrrrrrrrrrrrrr}+96 & +57 & +3 & -11 & +71 & -40 & +16 & -20 & -1 & -8 & +61 & +54 & 2.9 & -1.4 \\ +37 & +125 & -12 & -3 & +127 & +126 & -18 & -10 & +1 & 0 & +37 & +34 & 2.2 & 3.2 \\ +46 & +15 & -13 & -15 & +16 & -12 & -17 & +4 & -8 & +8 & +17 & -13 & -1.1 & -0.7 \\ +50 & +92 & -3 & +3 & -48 & +42 & +1 & +72 & +12 & +2 & +16 & -6 & -0.6 & 6.2\end{array}$

$\begin{array}{rrrrrrrrrrrrrr}+41 & +36 & -21 & -1 & -16 & +91 & +32 & +95 & -6 & +2 & +3 & +6 & 0.5 & 8.1 \\ +70 & +39 & -7 & -31 & +84 & -44 & +102 & -36 & +6 & -1 & +7 & -38 & 8.2 & -2.9 \\ +89 & +48 & +43 & +8 & +44 & +76 & +12 & +22 & -5 & -2 & -6 & +7 & 2.6 & 3.7 \\ +88 & +56 & +7 & -17 & +17 & +21 & -28 & +48 & -8 & +5 & +16 & +36 & 0 & 1.5\end{array}$

$\begin{array}{rrrrrrrrrrrrrr}+109 & +88 & -7 & -18 & -77 & +47 & -20 & -7 & -1 & -80 & +39 & -188 & -1.4 & -0.4 \\ +46 & +100 & -1 & -4 & -84 & -138 & -33 & -78 & -1 & +21 & +34 & +34 & -2.6 & -0.6 \\ +119 & +24 & -1 & -11 & +212 & +120 & -32 & +50 & +34 & -6 & +22 & +94 & 0.1 & 2.2 \\ +72 & +62 & -1 & -9 & +31 & +26 & +1 & +13 & +2 & -5 & +22 & +2 & 1.0 & 1.7 \\ 9 & 10 & 5 & 3 & 27 & 24 & 12 & 15 & 4 & 8 & 6 & 22 & 9 & 1.0 \\ & & & & & & & & & & & & & \end{array}$

had an excessively high postshunt hepatic blood flow rate (Table II) and might be a statistical outlier. Removing her data from analysis did not significantly change the pre- and postshunt glu-

Table V. Net Regional Exchange Rates*

\begin{tabular}{lccccc}
\hline & Splanchnic & & \multicolumn{2}{l}{ Renal } \\
\cline { 2 - 3 } \cline { 5 - 6 } & Pre & Post & & Pre & Post \\
\hline Glucose & $-577 \pm 96 \ddagger$ & $-695 \pm 116 \ddagger$ & $-4 \pm 23$ & $-93 \pm 43$ \\
Lactate & $+415 \pm 52 \ddagger$ & $+540 \pm 91 \ddagger$ & $+24 \pm 21$ & $+73 \pm 31 \ddagger$ \\
Pynuvate & $+41 \pm 9 \ddagger$ & $+49 \pm 10 \ddagger$ & $+5 \pm 15$ & $+9 \pm 3 \ddagger$ \\
Glycerol & $+84 \pm 12 \ddagger$ & $+86 \pm 8 \ddagger$ & $+44 \pm 4 \ddagger$ & $+56 \pm 4 \ddagger$ \\
Alanine & $+104 \pm 14 \ddagger$ & $+142 \pm 15 \ddagger$ & $-19 \pm 5 \ddagger$ & $-24 \pm 9 \ddagger$ \\
Glutamine & $+79 \pm 10 \ddagger$ & $\pm 151 \pm 44 \ddagger$ & $+90 \pm 18 \ddagger$ & $+68 \pm 16 \ddagger$ \\
Glutamate & $-42 \pm 10 \ddagger$ & $-36 \pm 8 \ddagger$ & $-1 \pm 5$ & $-6 \pm 6$ \\
Plasma FFA & $+218 \pm 47 \ddagger$ & $+261 \pm 43 \ddagger$ & $+33 \pm 28$ & $-1 \pm 25$ \\
Plasma & & & & \\
$\quad$ triglycerides & $-38 \pm 10 \ddagger$ & $-22 \pm 16$ & $-1 \pm 9$ & $+9 \pm 14$ \\
AcAc & $-204 \pm 48 \ddagger$ & $-365 \pm 115 \ddagger$ & $+5 \pm 7$ & $-4 \pm 9$ \\
$\beta$-OHB & $-181 \pm 36 \ddagger$ & $-214 \pm 91 \ddagger$ & $+26 \pm 8 \S$ & $+8 \pm 23$ \\
Total ketone & & & & \\
$\quad$ bodies & $-386 \pm 77 \ddagger$ & $-579 \pm 173 \ddagger$ & $+32 \pm 11 \S$ & $+4 \pm 30$
\end{tabular}

* Values are expressed as $\mu \mathrm{mol} / \mathrm{min}$ per $1.73 \mathrm{~m}^{2}$. Negative values (-) denote release while positive values $(+)$ denote uptake.

$¥$ Value statistically different from zero $(P \leq 0.05)$.

$\S$ Although the preshunt renal exchange rates for $\beta$-OHB and total ketone bodies are insignificant according to MANOVA test, there are significant removal rates according to the paired $t$ test. cose production rates $(604 \pm 102$ and $599 \pm 70 \mu \mathrm{mol} / \mathrm{min}$ per 1.73 $\left.\mathrm{m}^{2}\right)$, pre- and postshunt ketone-body production rates $(377 \pm 85$ and $488 \pm 173 \mu \mathrm{mol} / \mathrm{min}$ per $1.73 \mathrm{~m}^{2}$ ), or change the conclusions from this work.

In addition to these general observations pertaining to hepatic metabolism, we had other individual portal and renal venous findings which were surprising and striking. For example, the initial findings of higher glucose and ketone body concentrations in portal venous blood after a mesocaval shunt were discordant with general knowledge. However, the potential effect of reversing portal venous blood flow on substrate concentrations in portal

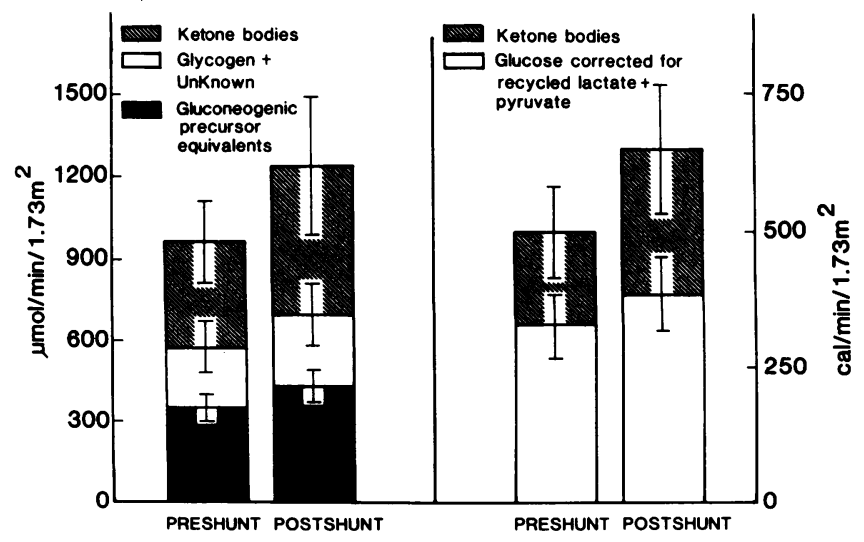

Figure 1. Splanchnic gluconeogenesis, glycogenolysis, and ketogenesis, and caloric equivalents of these processes, in cirrhotic patients preand postshunt. 
vein blood had not been recognized. Before surgical portasystemic shunts, all patients had hepatopedal (prograde) portal venous flow and small but predictable uptake of $\beta$-OHB and glutamine and release of alanine $(10,27)$. After surgical portasystemic shunts, the A-PV concentration differences for glucose and ketone bodies and their precursors varied widely between positive and negative values. Thus, interpretation of A-PV blood concentration differences became complex after surgical portasystemic shunting. Portal blood flow was hepatopedal after distal splenorenal shunts and was hepatofugal after mesocaval shunts. Norimally, blood from the portal veins and hepatic arteries courses through the liver parenchyma, mixes in the hepatic sinusoids, flows into the central veins, and exits through the hepatic veins (28). Cirrhosis increases the blood pressure in the hepatic sinusoids and augments arterial blood flow (29). Surgical mesocaval shunts decrease portal venous blood pressure and may reverse intrahepatic portal blood flow (30). Therefore, with retrograde portal venous blood flow the origin of portal blood may be derived not only from the extrahepatic splanchnic venous blood but also from hepatic arterial blood after it has transversed the liver (30). Postoperatively, and dependent upon from where the blood is sampled within the portal vein or its tributaries, a large increase in hepatic arterial blood flow rate (29), accompanied by retrograde portal blood flow, can functionaliy convert portal venous blood into hepatic venous blood in which the concentrations of glucose and ketone bodies are greater, while the concentrations of gluconeogenic and ketogenic precursors are less than those simultaneously present in the arterial blood. Thus, the site from which portal blood is sampled coupled with its directional flow influences the concentrations of precursors and products in this venous avenue.

The total number of carbon atoms in compounds measured that entered the kidney and left via the renal vein was approximately equal, but the precursor-product mixtures changed (Table IV). There was a consistent renal uptake of glycerol and glutamine, a tendency to extract lactate and pyruvate, and a uniform release of alanine. The exchange of glucose, triglycerides, and ketone bodies was inconsistent. The controlling mechanisms responsible for renal gluconeogenesis, lipogenesis, and/or ketogenesis are complex and not completely understood, but it appears essential for the kidney to have several ways, i.e., glucose, triglycerides, and ketone bodies, to release extracted and conserved blood substrates.

We have long held that the liver is the only major organ that makes a net contribution of ketone bodies to the blood. This conclusion was derived from many observations showing that arterial concentrations of AcAc plus $\beta-\mathrm{OHB}$ were greater than the venous concentrations of AcAc plus $\beta$-OHB across all vascular beds measured, i.e., brain (31), forearm (32), kidney (10, $33)$, and gut (10), except for the liver $(10,33)$. Hepatic ketogenesis is accomplished through the synthesis of AcAc (which equilibrates with $\beta$-OHB) via the $\beta$-hydroxy- $\beta$-methyl-glutaryl-CoA pathway (34). However, Landau and co-workers (35-37), in a series of experiments using specifically labeled $\left[{ }^{14} \mathrm{C}\right]$ palmitate, showed that the kidneys of diabetic rats could synthesize AcAc and $\beta-\mathrm{OHB}$ by direct deacylation of acetoacetyl CoA. In the present study, only one of 11 patients showed an unquestionable and large renal release of AcAc and $\beta-O H B$ (Table IV). After a $3-d$ fast and during the uncomplicated postoperative recovery period, this patient's production rates of AcAc and $\beta$-OHB were 80 and $186 \mu \mathrm{mol} / \mathrm{min}$ per $1.73 \mathrm{~m}^{2}$, respectively. The total quantity of ketone bodies $\left(266 \mu \mathrm{mol} / \mathrm{min}\right.$ per $\left.1.73 \mathrm{~m}^{2}\right)$ added to renal venous blood was $16 \%$ of the total quantity of ketone bodies $\left(1,714 \mu \mathrm{mol} / \mathrm{min}\right.$ per $\left.1.73 \mathrm{~m}^{2}\right)$ contributed to the blood by the liver in this patient. Unfortunately, the urinary excretion of AcAc and $\beta$-OHB was not measured.

Net production of ketone bodies by renal tissue may be unusual. Nonetheless, this patient's results clearly demonstrated the ability of the kidney to synthesize and release ketone bodies into the blood under stressful, catabolic circumstances.

In conclusion, this work demonstrates that $(a)$ hepatic gluconeogenesis, glycogenolysis, and ketogenesis may not be compromised by mesocaval or distal splenorenal shunt; that $(b)$ surgical mesocaval shunting with hepatofugal blood flow can convert the portal vein into a fuctional hepatic vein; and that $(c)$ kidney has the capacity to make a net contribution of ketone bodies to the blood.

\section{Acknowledgments}

This work was supported in part by U. S. Public Health Service grants AM25386, HL07198, AM19397, and RR00349, of the General Clinical Research Centers Branch, National Institutes of Health.

\section{References}

1. U. S. Department of Health, Education, and Welfare. 1974. Second Special Report to the U.S. Congress on Alcohol and Health. Publication No. 017-024000399.

2. Lebrec, D., T. Poynard, J. Bernuau, E. Bercoff, O. Nouel, J.-P. Capron, R. Poupon, M. Bouvry, B. Rueff, and J.-P. Benhamou. 1984. A randomized controlled study of propranolol for prevention of recurrent gastrointestinal bleeding in patients with cirrhosis: a final report. Hepatology. 4:355-358.

3. Burroughs, A. K., W. J. Jenkins, S. Sherlock, A. Dunk, R. P. Walt, T. O. K. Osuafor, S. Mackie, and R. Dick. 1983. Controlled trial of propranolol for the prevention of recurrent variceal hemorrhage in patients with cirrhosis. N. Engl. J. Med. 309:1539-1542.

4. Conn, H. O. 1984. Complications of portal hypertension. In Current Hepatology. G. Gitnick, editor. J. Wiley \& Sons, Inc., New York. 4:149-246.

5. Conn, H. O. 1984. Propranolol in portal hypertension: problems in paradise? Hepatology. 4:560-564.

6. MacDougall, B. R. D., D. Westaby, A. Theodossi, J. L. Dawson, and $R$. Williams. 1982. Increased long-term survival in variceal haemorrhage using injection sclerotherapy. Lancet. I:124-127.

7. Terblanche, J., P. C. Bornman, D. Kahn, M. A. T. Jonker, J. A. H. Campbell, J. Wright, and R. Kirsch. 1983. Failure of repeated injection sclerotherapy to improve long-term survival after oesophageal variceal bleeding. Lancet. II:1328-1332.

8. Conn, H. O. 1983. Endoscopic sclerotherapy: an analysis of variants. Hepatology. 3:769-771.

9. Health and Public Policy Committee, American College of Physicians. 1984. Endoscopic sclerotherapy for esophageal varices. Ann. Int. Med. 100:608-610.

10. Owen, O. E., F. A. Reichle, M. A. Mozzoli, T. Kreulen, M. S. Patel, I. B. Elfenbein, M. Golsorkhi, K. H. Y. Chang, N. S. Rao, H. S. Sue, and G. Boden. 1981. Hepatic, gut, and renal substrate flux rates in patients with hepatic cirrhosis. J. Clin. Invest. 68:240-252.

11. Reichle, F. A., and O. E. Owen. 1979. Hemodynamic patterns in human hepatic cirrhosis. Ann. Surg. 190:523-534.

12. Brannon, E. S., A. J. Merrill, J. V. Warren, and E. A. Stead, Jr. 1945. The cardiac output in patients with chronic anemia as measured by the technique of right atrial catheterization. J. Clin. Invest. 24:332336.

13. Owen, O. E., V. E. Trapp, G. A. Reichard, Jr., M. A. Mozzoli, 
J. Moctezuma, P. Paul, C. L. Skutches, and G. Boden. 1983. Nature and quantity of fuels consumed in patients with alcoholic cirrhosis. $J$. Clin. Invest. 72:1821-1832.

14. Garber, A. J., P. H. Menzel, G. Boden, and O. E. Owen. 1974. Hepatic ketogenesis in humans. J. Clin. Invest. 54:981-989.

15. Owen, O. E., B. S. B. Block, M. Patel, G. Boden, M. McDonough, T. Kreulen, C. R. Shuman, and G. A. Reichard, Jr. 1977. Human splanchnic metabolism during diabetic ketoacidosis. Metab. Clin. Exp. 26:381-398.

16. Owen, O. E., M. A. Mozzoli, G. Boden, M. S. Patel, G. A. Reichard, Jr., V. Trapp, C. R. Shuman, and P. Felig. 1980. Substrate, hormone and temperature responses in males and females to a common breakfast. Metab. Clin. Exp. 29:511-523.

17. Morrison, D. F. 1976. Multivariate Statistical Methods. Second ed. McGraw-Hill, Inc., New York. 141-153.

18. Smith, H. W. 1951. The Kidney Structure and Function in Health and Disease. Oxford University Press, New York. 399.

19. Sapir, D. G., and O. E. Owen. 1975. Renal conservation of ketone bodies during starvation. Metab. Clin. Exp. 24:23-33.

20. Owen, O. E., S. Caprio, G. A. Reichard, Jr., M. A. Mozzoli, G. Boden, and R. S. Owen. 1983. Ketosis of starvation: a revisit and new perspectives. Clin. Endocrinol. Metab. 12:359-379.

21. Marco, J., J. Diego, M. L. Villanueva, M. Diaz-Fierros, I. Valverde, and J. M. Segovia. 1973. Elevated plasma glucagon levels in cirrhosis of the liver. N. Engl. J. Med. 289:1107-1111.

22. Walker, C., W. Peterson, Jr., and R. Unger. 1974. Blood ammonia levels in advanced cirrhosis during therapeutic elevation of the insulin: glucagon ratio. N. Engl. J. Med. 291:168-171.

23. Sherwin, R., J. Prakash, R. Hendler, P. Felig, and H. O. Conn. 1974. Hyperglucagonemia in Laennec's cirrhosis. The role of portalsystemic shunting. N. Engl. J. Med. 290:239-242.

24. Chiasson, J. L., J. E. Liljenquist, B. C. Sinclair-Smith, and W. W. Lacey. 1975. Gluconeogenesis from alanine in normal postabsorptive man. Intrahepatic stimulatory effect of glucagon. Diabetes. 24: 574-584.

25. Huibregtse, C. A., G. A. Rufo, and P. D. Ray. 1977. Gluconeogenesis in rabbit liver. II. Gluconeogenesis and its enhancement by glucagon, epinephrine and cyclic AMP. Biochim. Biophys. Acta. 499:99110.
26. Chiasson, J. L., R. L. Atkinson, A. D. Cherrington, U. Keller, B. C. Sinclair-Smith, W. Lacy, and J. E. Liljenquist. 1979. Effects of fasting on gluconeogenesis from alanine in nondiabetic man. Diabetes. 28:56-60.

27. Felig, P. 1975. Diseases of the liver and biliary system. In Anatomy of the liver. Fifth ed. J. B. Lippincott Co., Philadelphia. 1-17.

28. Greenway, C. V., and R. D. Stark. 1971. Hepatic vascular bed. Physiol. Rev. 51:23-65.

29. Boyer, T. D. 1982. Portal hypertension and its complications. In Hepatology: A Textbook of Liver Diseases. D. Zakim and T. D. Boyer, editors. W. B. Saunders Co., Philadelphia, PA. 467.

30. Fulenwider, J. T., B. M. Nordlinger, W. J. Millikan, P. J. Sones, and W. Dean Warren. 1979. Portal pseudoperfusion. Ann. Surg. 189: 257-268.

31. Owen, O. E., A. P. Morgan, H. G. Kemp, J. M. Sullivan, M. G. Herrera, and G. F. Cahill, Jr. 1967. Brain metabolism during fasting. $J$. Clin. Invest. 46:1589-1595.

32. Owen, O. E., and G. A. Reichard, Jr. 1971. Human forearm metabolism during progressive starvation. J. Clin. Invest. 50:1536-1545.

33. Owen, O. E., P. Felig, A. P. Morgan, J. Wahren, and G. F. Cahill, Jr. 1969. Liver and kidney metabolism during prolonged starvation. $J$. Clin. Invest. 48:574-583.

34. Owen, O. E., S. Caprio, D. G. Sapir, T. K. Ray, C. R. Shuman, V. L. Schramm, R. D. Hoeldtke, and G. Boden. 1984. Ketogenesis and metabolic acidosis during diabetic ketoacidosis: new perspective. In Recent Advances in Obesity and Diabetes. N. Melchionda, editor. Raven Press, New York. 309-318.

35. Ohgaku, S., P. S. Brady, W. C. Schumann, G. E. Bartsch, J. M. Margolis, K. Kumaran, S. B. Landau, and B. R. Landau. 1982. A method for quantitating the contributions of the pathways of acetoacetate formation and its application to diabetic ketosis in vivo. J. Biol. Chem. 257:9283-9289.

36. Brady, P. S., R. F. Scofield, S. Ohgaku, W. C. Schumann, G. E. Bartsch, J. M. Margolis, K. Kumaran, A. Horvat, S. Mann, and B. R. Landau. 1982. Pathways of acetoacetate's formation in liver and kidney. J. Biol. Chem. 257:9290-9293.

37. Scofield, R. F., W. C. Schumann, K. Kumaran, and B. R. Landau. 1983. Ketone body production in diabetic ketosis by other than liver. Metab. Clin. Exp. 32:1009-1012. 